\title{
Lightning Rod Improvement Studies
}

\author{
C. B. Moore, William Rison, James Mathis, and Graydon Aulich \\ Langmuir Laboratory for Atmospheric Research, New Mexico Institute of Mining and Technology, \\ Socorro, New Mexico
}

(Manuscript received 15 December 1997, in final form 10 April 1999)

\section{ABSTRACT}

\begin{abstract}
Although lightning rods have long been used to limit damage from lightning, there are currently no American standards for the shape and form of these devices. Following tradition, however, sharp-tipped Franklin rods are widely installed despite evidence that, on occasion, lightning strikes objects in their vicinity. In recent tests of various tip configurations to determine which were preferentially struck by lightning, several hemispherically tipped, blunt rods were struck but none of the nearby, sharper rods were "hit" by lightning.

Measurements of the currents from the tips of lightning rods exposed to strong electric fields under negatively charged cloud bases show that the emissions consist of periodic ion charge bursts that act to reduce the strength of the local fields. After a burst of charge, no further emissions occur until that charge has moved away from the tip. Laboratory measurements of the emissions from a wide range of electrodes exposed to strong, normalpolarity thunderstorm electric fields show that positive ions are formed and move more readily over sharp-tipped electrodes than over blunter ones. From these findings, it appears that the electric field rates of intensification over sharp rods must be much greater than those over similarly exposed blunt rods for the initiation of upwardgoing leaders.

Calculations of the relative strengths of the electric fields above similarly exposed sharp and blunt rods show that although the fields, prior to any emissions, are much stronger at the tip of a sharp rod, they decrease more rapidly with distance. As a result, at a few centimeters above the tip of a 20 -mm-diameter blunt rod, the strength of the field is greater than that over an otherwise similar, sharper rod at the same height. Since the field strength at the tip of a sharpened rod tends to be limited by the easy formation of ions in the surrounding air, the field strengths over blunt rods can be much stronger than those at distances greater than $1 \mathrm{~cm}$ over sharper ones.

The results of this study suggest that moderately blunt metal rods (with tip height-to-tip radius of curvature ratios of about 680:1) are better lightning strike receptors than are sharper rods or very blunt ones.
\end{abstract}

\section{Introduction}

In 1747, Benjamin Franklin observed that he could discharge electrified objects in his parlor silently by approaching them with a sharp, metal needle in his hand. This discovery led him to suggest that thunderstorms similarly might be discharged by erecting sharp, metal rods beneath them, thus preventing lightning. When he tried this idea out under a thundercloud, however, one of his first rods was struck by lightning. He then proposed a different use for the rod; if it did not prevent lightning (which, demonstrably, it never does), an elevated, grounded rod might provide a preferred path to the earth for the strikes to a building. However, Franklin (1774) continued to advocate that the tips of his lightning rods be sharp, a practice that has continued to modern times. In the years since Franklin invented them,

Corresponding author address: C. B. Moore, Langmuir Laboratory for Atmospheric Research, New Mexico Institute of Mining and Technology, Socorro, NM 87801.

E-mail: moore@nmt.edu many of his rods have reduced lightning damage to structures, but it is recognized widely that objects in their vicinity sometimes are struck and that there still is no clear understanding of how a rod connects to an approaching lightning discharge.

As Franklin found, the application of strong electric fields to an exposed, sharp electrode such as a lightning rod causes an electric current to flow into the air; we now know that this current is a result of ionization processes in the air around the tip. The space charge formed by the ions created around the tip of a rod, however, acts to weaken the applied electric field. This weakening causes a problem for lightning protection efforts because very strong electric fields are required above a lightning rod to establish the conditions necessary for it to connect to approaching lightning. In the early 1930s, Schonland and Collens (1934) found that an upward-going return stroke usually is launched from an exposed object in the path of lightning approaching the earth. The conditions required for the conversion of the field-weakening emissions of ions from the air around the tip of a lightning rod into return strokes have not been established, and at the current time there is no consensus as 
to the optimal configuration of a lightning rod. In fact, the current National Fire Protection Association (NFPA) standard for the installation of lightning protection systems, NFPA 780 (1997), does not specify the form or the shape of a lightning rod.

\section{Investigations into lightning rod behavior}

In an effort to understand the function of lightning rods, several different approaches were used to investigate their behavior. These investigations, which are discussed below, included

1) arranging a competition between sharp and blunt rods exposed on a mountain ridge over which thunderclouds frequently formed to determine which would be struck preferentially by lightning,

2) measuring the currents that flowed from the earth to the tips of various lightning rods having different sizes and shapes,

3) high-speed digitizing and recording of these currents to selected rods,

4) making laboratory measurements of the discharges from ellipsoidal electrodes,

5) analyzing theoretically the electric fields around ellipsoidal electrodes prior to discharge onset,

6) examining the point discharge and return-stroke initiation processes, and

7) applying the findings toward the design of improved lightning rods.

The efforts thus far have been directed toward a study of protection against normal-polarity lightning in which a negatively charged, stepped leader descends from the negatively charged lower regions of a thundercloud and provokes the emission of a positively charged "returnstroke" leader from exposed objects on the earth below. Thus far in the measurements, none of the less frequent, positive lightning discharges such as those that sometimes occur in the dissipating stages of a thunderstorm and in tornadic storms have been encountered. As a result, no study of positive lightning has been made.

The field portions of this study were carried out near the 3287-m-high summit of South Baldy Peak in the Magdalena Mountains of central New Mexico. The recording instruments used in the study were installed in Kiva II, a steel-walled room buried near the summit. A summary describing each of these investigations follows.

\section{a. A lightning-reception competition between sharp and blunt lighting rods}

During the past five years, a number of differently shaped rods were exposed to the atmospheric electric fields over South Baldy in an effort to determine which shape of lightning rod would be preferentially struck by lightning produced by the summer thunderstorms. In these tests, sharply tipped Franklin rods were exposed, with blunter rods mounted nearby (with distances ranging from 5 to $20 \mathrm{~m}$ ). Five blunt rods were used in 1994, seven in 1995, and eight in 1996, 1997, and 1998.

\section{1) DesCription OF THE LIGHTNING ROD INSTALLATIONS}

Each of the lightning rods used in this effort was mounted on a nylon insulator inserted in the top of a 6.1-m-high metal mast constructed of nominal 44-mmdiameter electrical conduit. Each rod was connected to the earth by a copper-wire "down conductor" in which either a 2-A fuse or a lightning flash counter was inserted to provide indications of any direct lightning strike. (A subsequent "blown" fuse was sufficient evidence of a strike.)

The Franklin rods used in this study were standard, Underwriters Laboratory, Inc., (UL)-approved, lightning rods obtained from the East Coast Lightning Equipment Co. of Winsted, Connecticut. Most of the rods were made of aluminum round stock; a few of them were copper. The rods were $12.7 \mathrm{~mm}$ in diameter and $305 \mathrm{~mm}$ in length. The upper section of each rod had been tapered toward its tip, with the tapers starting about $76 \mathrm{~mm}$ from the top and continuing until the diameter was reduced to about $3.5 \mathrm{~mm}$. The top of each rod then had been roughly machined into a cone with an included angle of approximately $45^{\circ}$. Although the conical tips initially were very sharp, after exposure to the weather and to strong electric fields beneath thunderclouds, these tips generally became somewhat less sharp. The radii of curvature for several rods observed after exposure during this study were measured and found to be about $0.1 \mathrm{~mm}$, a value that is used later in some calculations.

The blunter rods that were used in this competition were made from round stock with heights of $305 \mathrm{~mm}$ and with diameters ranging from 9.5 to $51 \mathrm{~mm}$. Most of the rods were made of aluminum but others made of brass and of stainless steel also were used. The upper ends of all the blunter rods were machined such that the top became a hemisphere with the same diameter as the parent round stock. After machining, the hemispheres and the upper-cylindrical portions of each rod were polished to a mirror finish to eliminate any protrusions that would concentrate the electric fields locally. When these rods were installed on top of the 6.1-m-high masts, all of their tips were at heights of 6.4 $\mathrm{m}$ above ground level.

\section{2) LightNing STRIKES TO THE COMPETING LIGHTNING RODS}

In 1994, a 19-mm-diameter aluminum, blunt rod on a 6.1-m-high mast located between two similarly mounted, sharply tipped, proprietary "air terminals" was struck by lightning initiated aloft by a small rocket towing an ungrounded, 90-m length of fine wire. A discharge propagated both above and below the ends of 


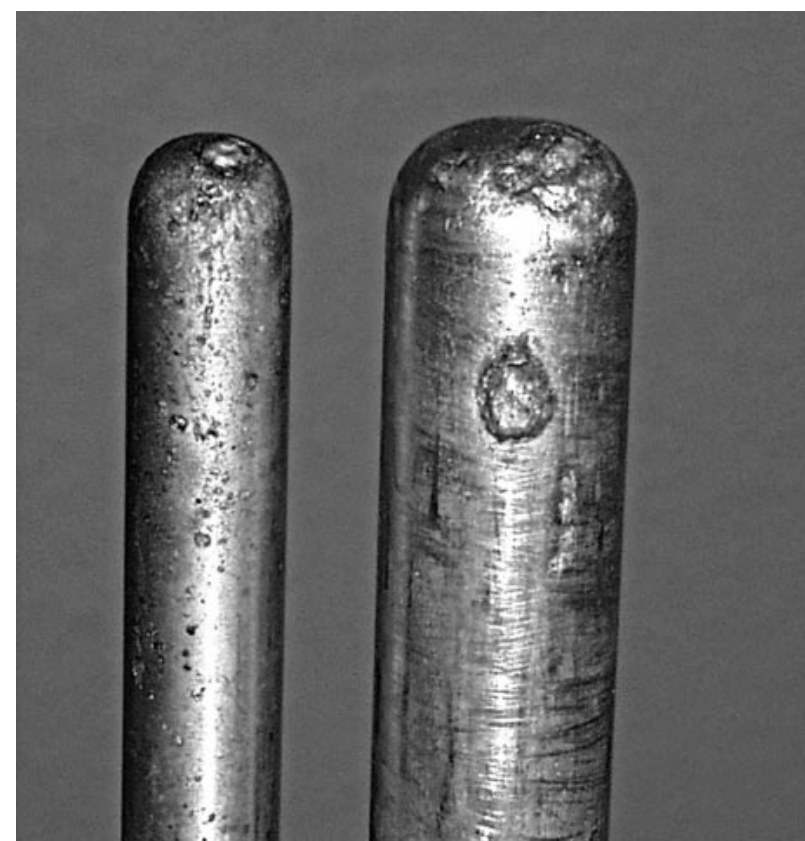

FIG. 1. Photograph of two blunt rods that were struck by lightning while they were mounted on top of 6.1-m-high masts. The left-hand rod was $12.7 \mathrm{~mm}$ in diameter; the right-hand one was $19 \mathrm{~mm}$ in diameter.

the wire, creating a large lightning discharge that connected to the blunt rod.

During the 1996 summer thunderstorms, four aluminum rods with blunt tips adjacent to sharper Franklin rods participated in cloud-to-ground discharges at different times. Two of these instances were strikes caused by natural lightning that blew fuses and produced weld marks on the hemispherical tips of two different 19mm-diameter rods. The third instance was a discharge from another 19-mm-diameter rod to a rocket aloft trailing a short length of ungrounded wire. An unaffected sharp rod was exposed on a similar mast located at a distance of $5.5 \mathrm{~m}$ away. The fourth incident involving a blunt rod was the activation of a strike counter in the down conductor from a $25.4-\mathrm{mm}$-diameter rod during a thunderstorm that occurred when no observers were in the Kiva area.

In 1997, four blunt rods again participated in lightning discharges that missed the sharp rods nearby. A 12.7-mm-diameter aluminum rod was struck twice and a $19-\mathrm{mm}$ rod was struck once when lightning was initiated by rockets that injected grounded wires into the air beneath thunderclouds; the lightning traveling down the grounded wires transferred over to the blunt rods and produced weld marks on their hemispherical tips. A natural strike hit a $12.7-\mathrm{mm}$-diameter rod on 10 September 1997. Sharp-tipped, aluminum Franklin rods were located within a few meters of the blunt rods but none of them participated in any of these strikes. Figure 1 is a photograph of two of the blunt rods that were struck during this competition.

\section{b. Measurements of the currents flowing to the tips of} lightning rods

In this study, eight rods with different configurations were investigated during three different summer thunderstorm seasons. Each lightning rod was connected to the earth through a $10-\mathrm{k} \Omega$ resistor and a $2-\mathrm{A}$ fuse by a number-10 wire. A blown fuse provided proof of a lightning strike to the rod. The voltage drop across the resistor, used to measure the current flows from the earth to the rod, was transferred into the Kiva through a differential amplifier and was recorded digitally at the rate of 5 measurements per second. As may be expected, the greater currents flowed to the rods with the sharper tips. The currents to the UL-approved, sharp-tipped Franklin rods commenced when the ambient electric field became stronger than $2 \mathrm{kV} \mathrm{m}^{-1}$ and increased to values of about $15 \mu \mathrm{A}$ under field strengths in excess of $10 \mathrm{kV} \mathrm{m}^{-1}$. The blunt rods that were exposed also emitted discharges under strong fields, but the field strengths required for the current onsets usually were in excess of $5 \mathrm{kV}$ $\mathrm{m}^{-1}$; the emissions under strong electric fields were on the order of $5 \mu \mathrm{A}$ or less.

Although these currents may seem trivial, the amount of charge that they release into the air around the tip is equivalent to that necessary for canceling the ambient electric field over a surface area at the rate of more than $100 \mathrm{~m}^{2} \mathrm{~s}^{-1}$. The effect of the concentrated charges emitted around the tip of one of these rods obviously limits the strength of the local electric field.

\section{c. Digitized measurements of the currents flowing to lightning rods}

\section{1) INSTRUMENTATION}

Because the time resolution of the current-measuring recorder was poor, a high-speed digitizer was obtained and used to measure the currents flowing to the tips of three differently shaped rods during lightning strikes near Kiva II. The digitizer, an Innovative Integration model PC 31, contained two analog-to-digital channels. The inputs to each of these channels were multiplexed so that the system allowed digitization of four input signals, each at a $2-\mathrm{MHz}$ rate. The three lightning rods used in this study were placed around the periphery of Kiva II and were arranged so as to be at the vertices of an equilateral triangle with legs $5.5-\mathrm{m}$ long. During the 1996 study, one of these rods was a 12.7-mm-diameter, UL-approved Franklin rod with a tip sharpened into a $45^{\circ}$ cone. The second rod was a $19-\mathrm{mm}$-diameter, cylindrical, brass rod with its upper tip rounded into a hemisphere. The third rod was made of stainless steel, was $50.8 \mathrm{~mm}$ in diameter, and its tip again was rounded into a hemisphere.

The lower end of each of these three rods was fitted with set screws to capture the upper end of a wire that was used as a coaxial down conductor and was passed down inside the steel conduit mast. Each of these down 


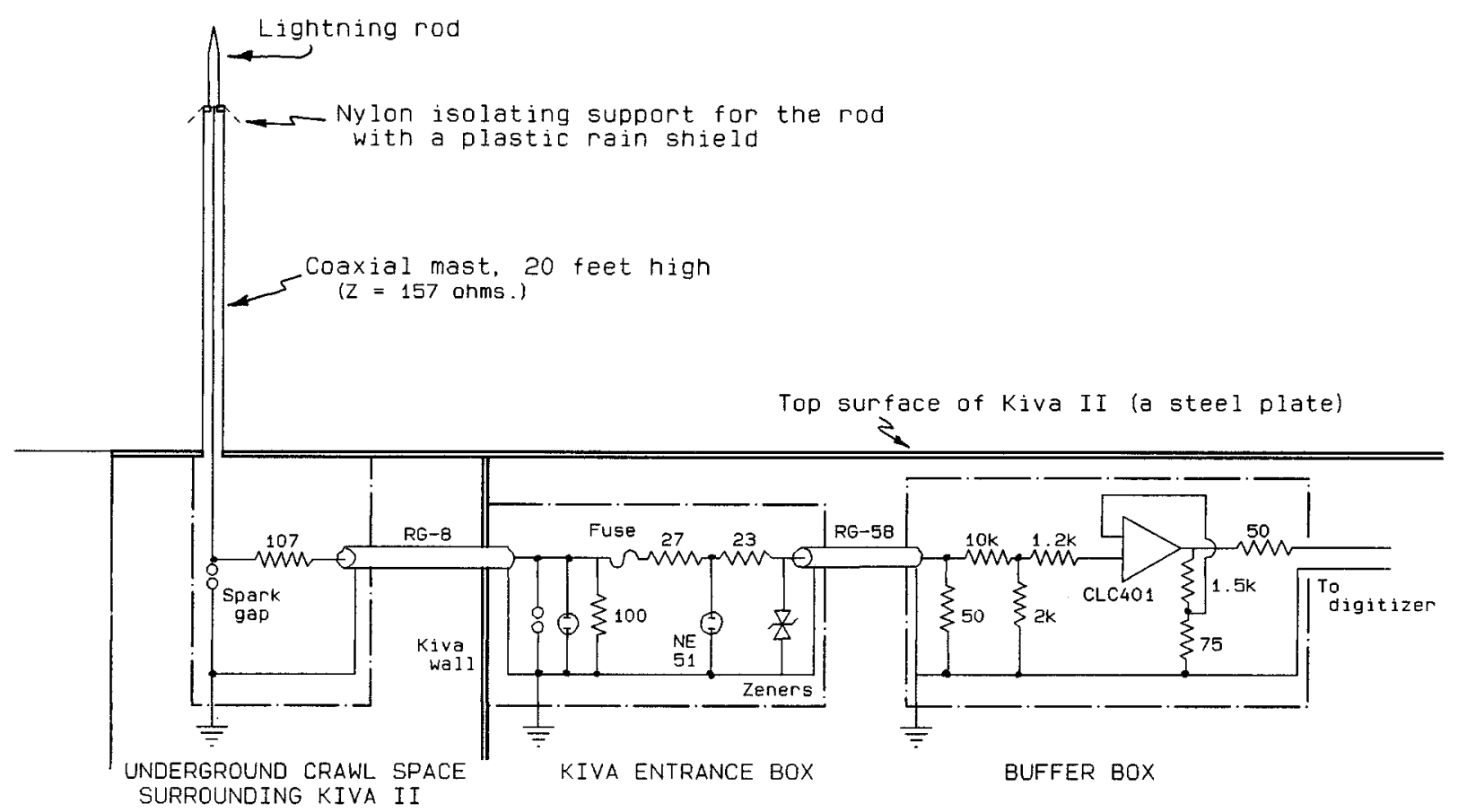

FIG. 2. The circuit diagram for the connection between each lightning rod and the digitizer. (Note: the resistance values are given in ohms.)

conductors extended below the mounting socket to a "spark-gap" box in the space beneath the skirt surrounding Kiva II. The purpose of the coaxial conduits and the spark-gap boxes was to allow sensitive measurements of the currents that flowed to the tips in the intervals just before a lightning strike to one of the terminals to be made without suffering major damage to the measuring instrumentation once a strike occurred. From the Kiva-entrance box, the signals were led to a voltage-dividing, $50-\Omega$ termination and a voltage-follower buffer circuit that was connected to the four-channel digitizer. The schematic diagram for the currentmeasuring circuit is shown in Fig. 2.

The change in ambient electric field outside Kiva II was sensed by an isolated, circular electrode that was mounted in an inverted housing about $1 \mathrm{~m}$ above the earth. This electrode was connected to the earth through an operational amplifier that measured the displacement currents caused by changes in the local electric field. The signal from the field-change sensor also was terminated in $50 \Omega$ at the input of the fourth buffer. The output from this buffer fed the fourth channel of the digitizer and a trigger generator consisting of a differentiator, a rectifier, and a comparator with an adjustable threshold.

Whenever the time rate of change in the electric field signal exceeded the preset threshold, the generator provided a trigger to the digitizer that then stored four channels of digitized data for a 1-s period around the time of the trigger. In an effort to capture a record of the initiation of each discharge, the system was set up to record about $130 \mathrm{~ms}$ of data from each channel prior to the trigger and about $900 \mathrm{~ms}$ afterward. The system thus operated automatically in capturing data on the nearby lightning strikes that produced electric-field rates of change greater than the preset threshold.

\section{2) Current measurements}

During the late summer of 1996, more than 50 datasets were recorded from lightning within about $2 \mathrm{~km}$ of the summit but none of these discharges struck any of the air terminals or the area directly around the summit. Examples of some of the data collected are shown in Figs. 3, 4, and 5. The currents that were measured included both the displacement currents caused by changes in the ambient electric fields and the charge emissions associated with the creation of ions around the tips. As shown by these and other recordings, the sharp Franklin rod emitted strong bursts of positive charge during the close approach of an initiating stepped leader that descended from the thundercloud overhead. On the other hand, there were no similar pulsed emissions from the blunter rods during the approach of these negative leaders, although large displacement currents to the blunt rods were recorded during the initiation of the strikes. The current excursions shown in Fig. 3 for the $19-\mathrm{mm}$ and the $51-\mathrm{mm}$ rods just prior to the strike are due largely to displacement currents induced by rapid changes in the electric field associated with the approaching lightning. 

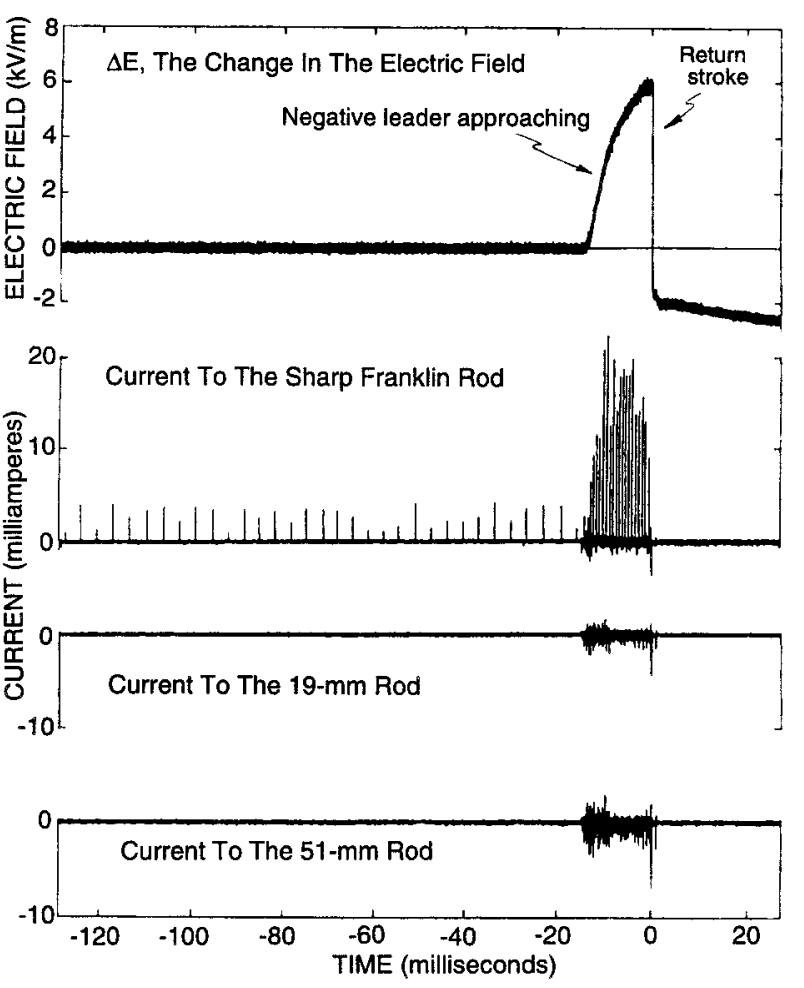

FIG. 3. Plots of the change in the atmospheric electric field strength on 7 Sep 1996 at the start of a lightning strike near South Baldy Peak and of the currents that flowed to the tips of three lightning rods exposed on top of 6.1-m-high masts. The height-to-tip radius ratio for the Franklin rod was about $64000: 1$; the ratio for the $19-\mathrm{mm}$ diameter rod was $680: 1$ and that for the $51-\mathrm{mm}$-diameter rod was 250:1. The strength of the electric field at the tip of the Franklin rod was calculated to be enhanced over the ambient field by a factor $k_{e}$ of about 12 250; over the $19-\mathrm{mm}$ rod, $k_{e}$ was calculated to be 230 , and over the 51-mm rod, $k_{e}$ was 102.

\section{d. Laboratory studies of discharges from ellipsoidal electrodes subjected to strong electric fields}

In an effort to make quantitative determinations of the relations between the strength of the applied electric fields and the emitted point discharge currents without the perturbations caused by variable winds blowing on the electrodes, the investigation was transferred to the Socorro laboratory. The laboratory study was limited to an investigation of positive discharges, because most lightning return strokes develop from the emissions of positive charges from the ground strike point. Further, we chose to use prolate, semiellipsoidal electrodes for this part of the study because, as is discussed later (in section 5), the potential function for this shape is known (Smythe 1950,168-169) and the strength of the electric fields around their tips could be calculated.

Four such brass electrodes, with tip radii of 0.0625 , $0.125,0.25$, and $0.5 \mathrm{~mm}$, respectively, were turned on a computer-controlled lathe. Further, in an effort to obtain an electrode with an even smaller tip radius, a steel needle also was used; its tip was ground and polished until it appeared to be that of a prolate ellipsoid with a
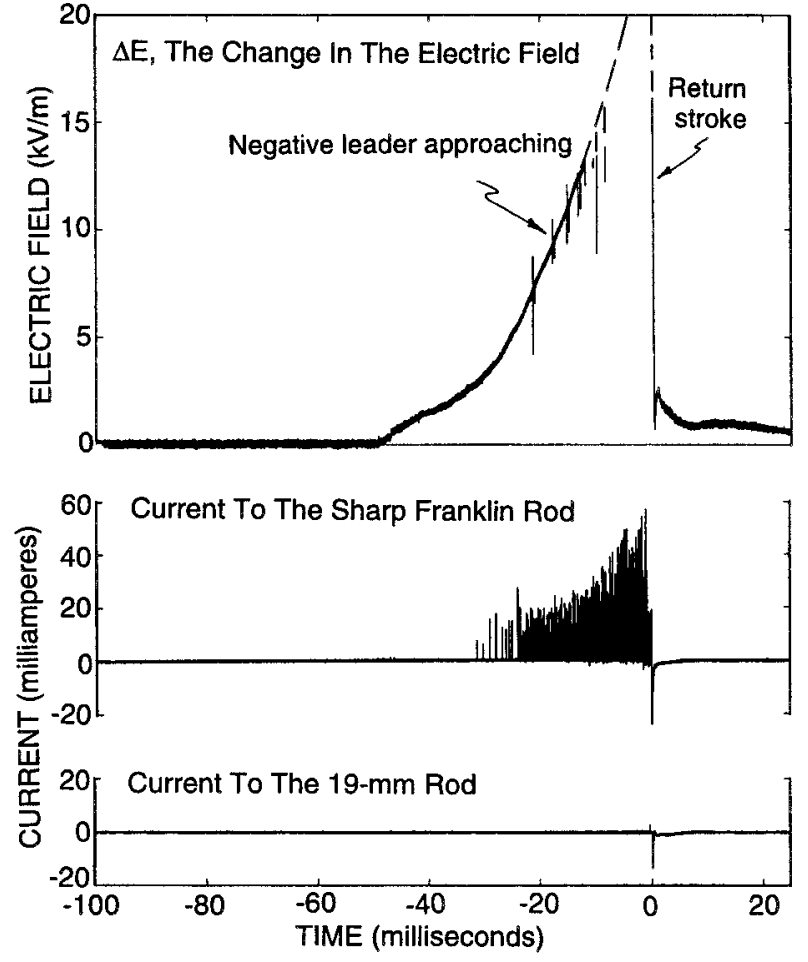

FIG. 4. Plots of the change in the atmospheric electric field at 1730 MST 25 Aug 1996 at the start of a lightning strike near South Baldy Peak and of the currents that flowed to the tips of two lightning rods exposed on 6.1-m-high masts.

radius of curvature of approximately $0.01 \mathrm{~mm}$, as determined with a microscope. The height of each electrode used in this study was $141 \mathrm{~mm}$.

Each electrode was placed, in turn, upright on, but isolated with a thin Mylar sheet from, a horizontal, 1- $\mathrm{m}^{2}$ aluminum plate that was connected to the earth. A second, $1-\mathrm{m}^{2}$ parallel plate was mounted on insulators 295 $\mathrm{mm}$ above the lower plate. The electrode under test was connected to the earth through a $9875-\Omega$ resistor; the voltage drops across this resistor were measured with a digital voltmeter and with a digital oscilloscope to obtain information on the current flows from the electrode. Negative voltages $V$ of up to $30 \mathrm{kV}$ then were applied to the upper plate, creating positive (upwardly directed) electric fields in the space between the plates with strengths that could be controlled between zero and 100 $\mathrm{kV} \mathrm{m}^{-1}$. The electric fields thus created, $V_{\text {applied }}$ divided by the plate separation, are the "applied electric fields" that are discussed below.

A typical plot of the currents emitted from the ellipsoid with the 0.0625 -mm-radius tip is shown in Fig. 6 in which it can be seen that, above a threshold, the current varies with the square of the applied electric field strength. This square-law dependence was first noted by Warburg (1899), who found a relation between the voltages $V$ he applied to sharpened electrodes in his laboratory to create the controlling electric fields and 

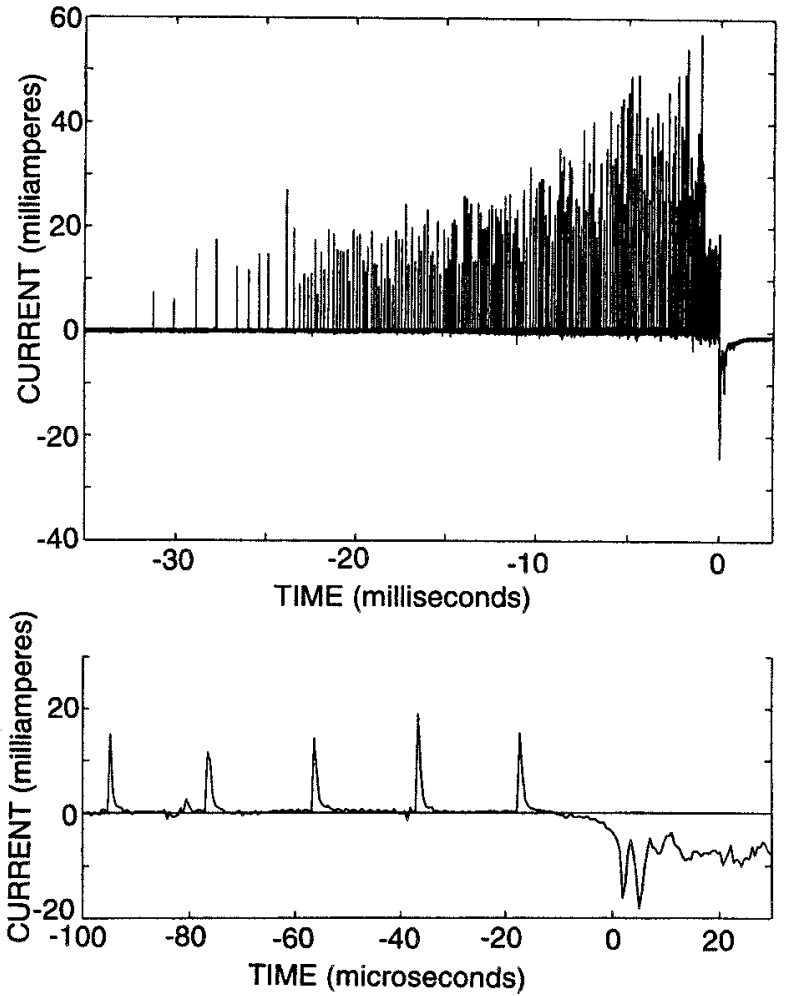

FIG. 5. Expanded portions of the Franklin rod current plot shown in Fig. 4. At $20 \mathrm{~ms}$ before the strike, the mean interval between the bursts of current was about $100 \mu \mathrm{s}$, but the interval decreased to 16 $\mu \mathrm{s}$ in the last ms before the return stroke was initiated from some other nearby object.

the currents $C$ that flowed into the air surrounding the electrode,

$$
C=a_{0} V(V-M),
$$

where $a_{0}$ was a coefficient that depended on the spacing between the electrode tip and a collecting plate, and $M$ was the threshold voltage required for the onset of the discharge from the point. Later measurements by Chapman and Pilié (Chapman 1955), using elevated electrodes mounted between parallel metal plates across which voltages were applied to create strong electric fields, indicated that, in still air, the point discharge current $I$ varies with the applied electric field $E_{0}$ as

$$
I=A\left(E_{0}-E_{\text {threshold }}\right) E_{0},
$$

where $A$ is a constant of proportionality for a given electrode.

The dependence of the measured point discharge currents on the square of the applied field strength is demonstrated graphically using Pilié's approach in Fig. 7 in which the emitted currents $I$ divided by the strengths of the applied electric field $E_{0}$ are plotted versus $E_{0}$. These plots prompted careful examination of the discharges; several interesting phenomena then were found as the strength of the applied electric field was increased slow-

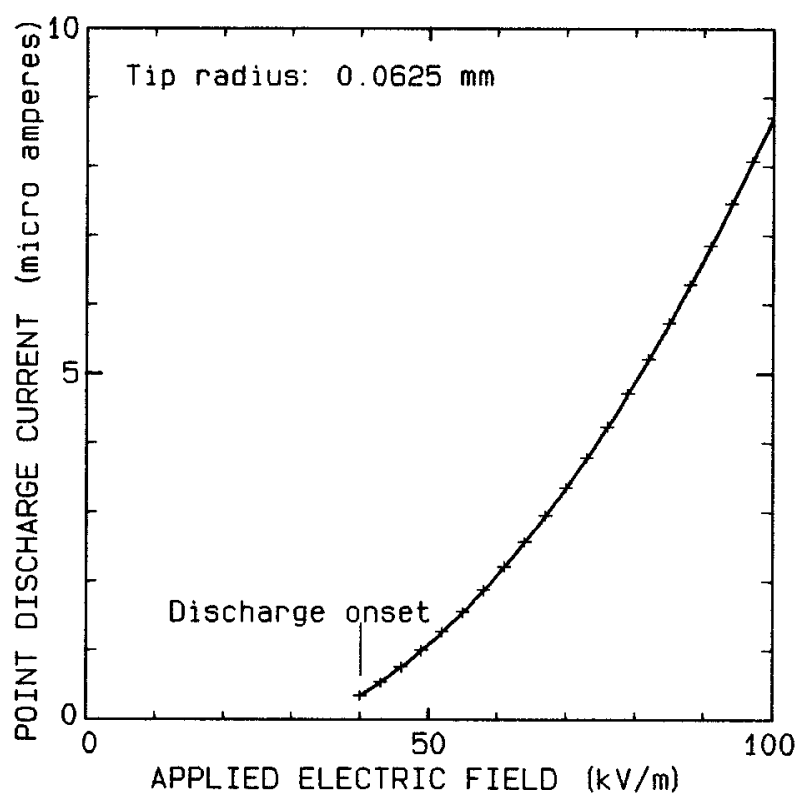

FIG. 6. Plot of the point discharge current emitted under the influence of a positive electric field from a prolate semiellipsoidal electrode with a tip radius of curvature of $0.0625 \mathrm{~mm}$. The tip of the electrode was $141 \mathrm{~mm}$ above the ground plane on which it was mounted. The tip height-to-tip radius ratio was 2260:1; the calculated strength of the electric field at the tip was 634 times that of the ambient field.

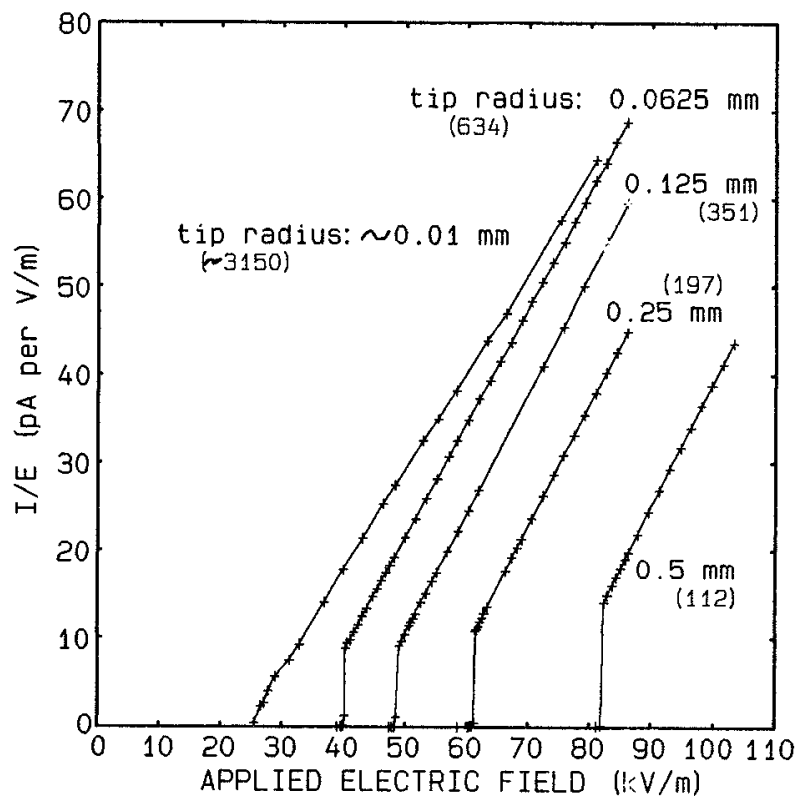

FIG. 7. Plots of the point discharge currents $I$ divided by the applied electric field $E$ vs $E$ for five different prolate, semiellipsoidal electrodes subjected to varying electric fields oriented in the direction of the ellipsoids' major axes. Each electrode was $141 \mathrm{~mm}$ high. The numbers in parentheses are the calculated electric field enhancement factors $k_{e}$ at the tip of each electrode. These plots show that $I$ varies with $E^{2}$ when $E$ is greater than the threshold required for discharge onset. 
TABle 1. Characteristics of the $I / E$ vs $E$ data in Fig. 7.

\begin{tabular}{cccccc}
\hline \hline & $\begin{array}{c}\text { Field strength at onset } \\
\text { of steady current } \\
\left(\mathrm{kV} \mathrm{m}^{-1}\right)\end{array}$ & $\begin{array}{c}\text { Slope of } \\
I /\left[\left(E_{0}-E_{\text {intercep })} E_{0}\right]\right. \\
{\left[\mathrm{fA}\left(\mathrm{V} \mathrm{m}^{-1}\right)^{-2}\right]}\end{array}$ & $\begin{array}{c}E_{\text {intercept with } E} \\
\text { axis }\left(\mathrm{kV} \mathrm{m}^{-1}\right)\end{array}$ & $\begin{array}{c}\text { Peak frequency } \\
\text { of bursts }\left(\mathrm{s}^{-1}\right)\end{array}$ & $\begin{array}{c}\text { Approximate min } \\
\text { period between } \\
\text { bursts }(\mathrm{ms})\end{array}$ \\
\hline$\sim 0.01$ & 25.47 & 1.134 & 24.2 & $\sim 2900$ & 0.35 \\
0.0625 & 40.24 & 1.308 & 33.5 & $\sim 100$ & $\sim 10$ \\
0.125 & 49.00 & 1.362 & 42.2 & $\sim 5$ & - \\
0.25 & 61.34 & 1.384 & 53.5 & sporadic & - \\
0.50 & 82.23 & 1.414 & 72.2 & $\sim 00$ & - \\
\hline
\end{tabular}

ly. No currents above the detection threshold of 0.01 $\mu \mathrm{A}$ were detected from any of the electrodes until the applied field became very strong. When the field applied to the sharp, steel needle exceeded $25 \mathrm{kV} \mathrm{m}^{-1}$, sporadic, short-duration bursts of current (with peak amplitudes of about $1 \mu \mathrm{A}$ and durations of less than $0.5 \mu \mathrm{s}$ ), were detected by the oscilloscope; these discharges increased in amplitude and frequency as the field strength was increased slowly. The periods between the pulses decreased to about $0.35 \mathrm{~ms}$ and the mean currents attained levels of about $0.2 \mu \mathrm{A}$ when the applied field strength exceeded $30 \mathrm{kV} \mathrm{m}^{-1}$. Then, as the field strength was increased still further, the voltage drop across the resistor increased, indicating increased current emissions, but the bursts had ceased. When the needle tip was examined in the dark, a faint luminosity could be seen around the tip that indicated that the discharge regime had changed from the "charge-burst" mode to the "glow" regime described by Hermstein (1960).

In the glow regime, ionization of the air occurs continuously at the electrode tip under the influence of the very strong, local, electric fields. Electrons liberated from neutral molecules fall into the tip while the resulting positive ions migrate away under the influence of the fields without causing further ionization. (The positive ions are so massive, about 60000 times the mass of an electron, that they are not accelerated sufficiently for ionization under the influence of the electric fields around an electrode in the glow regime.) In this regime, as the field strength was increased further, the ratio of emitted current to the applied field strength increased linearly with the field strength excess above the glow-regime onset threshold, as shown in Fig. 7.

The blunter, brass electrodes showed a somewhat similar behavior with increasing field strength except that the burst regimes occurred over increasingly narrower ranges of field strength as the tip radius increased; with the 0.5 -mm-radius electrode, the mean current increase from 0.01 to $1.1 \mu \mathrm{A}$ took place with a field strength change of about $1 \mathrm{kV} \mathrm{m}^{-1}$. The current flows from all of these electrodes became continuous at field strengths greater than the $E_{\text {onset }}$ level. Characteristics of the linear plots shown in Fig. 7 are listed in Table 1. The slope for each of these plots was determined by a least-squares fit to the data. Note that no emissions were detected at field strengths weaker than those at which the linear plots would intercept the $E$ axis in Fig. 7; $E_{\text {intercept }}$ for a given electrode appears to be the strength of the ambient electric field below which existing discharges extinguish. These laboratory measurements suggested that an examination of the discharge processes would be worthwhile, starting with the earlier studies of positive point discharges done by Kip and Loeb.

\section{Sudden current onsets and Kip's studies of positive point discharges}

The sudden onset phenomenon was discovered by Kip $(1938,1939)$, who also provided an explanation for the initiation of positive point discharges. He demonstrated that the onset of positive emissions depended on the availability of free electrons in the air around the electrode tip. When a free electron appeared in the air above an electrode subjected to a strong electric field, it would be accelerated toward the tip, liberating electrons from neutral molecules in its path. These new electrons, in turn, accelerated toward the tip, liberating even more electrons and resulting in an avalanche of electrons that left the newly electron-deficient gas molecules behind as a column of more slowly moving, positive ions. Kip found that the free electrons necessary to initiate an electron avalanche could arise from cosmic rays, from radioactive emissions in the air, or, more readily, by the action of strong electric fields, which could extract electrons from existing negative ions in the vicinity.

Loeb (1935) earlier had found that negative oxygen ions gave up free electrons whenever the strength of the local electric field exceeded $6.8 \mathrm{MV} \mathrm{m}^{-1}$ under a pressure of $1 \mathrm{~atm}$ and that the critical field strength varied with the atmospheric pressure. Kip established that the critical ratio of field strength $E$ to air pressure $p$ for the onset of positive discharges was an $E / p$ of $90 \mathrm{~V} \mathrm{~cm}^{-1}$ torr $^{-1}$, in the units used by the early investigators into point discharges.

These findings provide an explanation for the periodic bursts of charge from a sharp lightning rod shown in Fig. 4 and for the point discharge current dependence on the excess of the ambient field strength above some threshold value. Both of these features arise because the initiation of an electron avalanche requires much stronger fields than those required to continue the process. The continuing electron avalanches in this phase leave a positive ion space charge in the air around the tip that increases until it is approximately equivalent to the dif- 
ference between the initial displacement charge on the tip at the onset and that left on the tip at the time when the avalanches cease (because of the weakening of the field by the space charge accumulation). No further emissions occur until this space charge moves away from the tip; it migrates away under the influences of the residual electric fields and any wind moving past the tip, and as a result of the ions' repulsive forces away from each other. After enough of this charge has been removed so that it no longer shields the tip, the field strength there can rise again above the $E / p$ of $90 \mathrm{~V} \mathrm{~cm}^{-1}$ torr $^{-1}$, whereupon a new electron avalanche may occur, and a new burst of shielding positive ions is created. In this mode, the electrode-air system under a strong electric field acts as a relaxation oscillator.

After an electron avalanche is initiated, it makes many free electrons available. (During the individual avalanche episodes observed at the current onsets shown in Fig. 5, charge bursts on the order of $10 \mathrm{nC}$ were measured, which indicates that about $6 \times 10^{10}$ electrons had arrived at the tip following the liberation of the single, avalanche-initiating, "seed" electron.) Once started, the avalanche process can continue until, according to Kip (1938), the strength of the electric field at the tip is decreased below an $E / p$ ratio of about 30 $\mathrm{V} \mathrm{cm}{ }^{-1}$ torr $^{-1}$ (about $22 \mathrm{~V} \mathrm{~m}^{-1} \mathrm{~Pa}^{-1}$ ), equivalent to a field strength of less than $2.3 \mathrm{MV} \mathrm{m}^{-1}$ at an electrode tip under $1 \mathrm{~atm}$. Harrison and Geballe (1953) later found that $30 \mathrm{~V} \mathrm{~cm}^{-1}$ torr $^{-1}$ was the level at which ionization and electron attachment in air become about equally probable.

If, however, the ambient field around the tip has intensified rapidly enough, additional electron avalanches can form in the air ahead of the positive space charge, creating more positive ions, which, in turn, create new avalanches at ever greater distances from the tip. This process can result in the formation of a positive streamer that can propagate on its own under the influence of the ambient electric fields. Phelps $(1971,1974)$ found that, after initiation between parallel plates, a positive discharge will propagate in the direction of the field whenever the local field is stronger than $400 \mathrm{kV} \mathrm{m}^{-1}$ (at 1 atm pressure). In weaker fields, the streamers he introduced quickly extinguished. Allen and Ghaffar (1995) have refined Phelps's measurement by eliminating the field contribution around the initiating electrode; they determined the critical field strength for streamer propagation in the regions remote from the source to be 440 $\mathrm{kV} \mathrm{m}^{-1}$, which is equivalent to an $E / p$ of $5.8 \mathrm{~V} \mathrm{~cm}^{-1}$ torr $^{-1}\left(4.3 \mathrm{~V} \mathrm{~m}^{-1} \mathrm{~Pa}^{-1}\right)$.

These measurements aid in understanding why the nimbus of light around a point in discharge is limited to the space within a few millimeters of the tip. The end of the luminosity marks the region where the field strength has decreased below the level required for creating electron avalanches; the luminosity itself occurs in the region where avalanche-produced electrons are exciting the air molecules and recombining with positive ions.

The findings by Loeb, Phelps, Allen, and others that there are critical ratios of electric field strength to atmospheric pressure raise questions as to what factors determine a given ratio and about what energies are involved. We now turn to a consideration of the significance of the $E / p$ values that have been reported.

\section{The energy equivalents of $E / p$ values}

The dependence of the critical electric field strengths on the atmospheric pressure is determined by the length of the mean free path that a charged particle such as an ion can travel under the influence of the electric field between collisions with air molecules. From this perspective, values of $E / p$ can be considered as measures of the mean potential difference traversed by an ion in one mean free path. Consider an $E / p$ value of $1 \mathrm{~V} \mathrm{~cm}^{-1}$ torr $^{-1}$. Conversion of this value into mks units yields

$$
E / p=1 \mathrm{~V} \mathrm{~cm}^{-1} \text { torr }^{-1}=0.75 \mathrm{~V} \mathrm{~m}^{-1}\left(\mathrm{~N} \mathrm{~m}^{-2}\right)^{-1} \text {. }
$$

From the gas law, the atmospheric pressure $p$ is a function of the gas molecule concentration $n$ and the Kelvin temperature $T ; p$ is defined by

$$
p=n k T,
$$

where $k$ is Boltzmann's constant: $1.38 \times 10^{-23} \mathrm{~J} \mathrm{~K}^{-1}$. Multiplying Eq. (3) through by $p$ gives

$$
E_{@ 1 \mathrm{~V} \mathrm{~cm}}^{-1} \text { torr }^{-1}=0.75 n k T \mathrm{~V} \mathrm{~m} \mathrm{~N}{ }^{-1} .
$$

Now, from Cobine (1958, p. 36), the mean free path $L$ of a rapidly moving oxygen ion is

$$
L=\frac{1}{n \sigma},
$$

where $\sigma$ is the collision cross section for a rapidly moving oxygen ion [about $4.3 \times 10^{-19} \mathrm{~m}^{2}$, calculated from Loeb's data given in Cobine (1958, p. 23)]. The negatively charged ions from which electrons may be liberated are probably those of oxygen and water vapor because they compose most of the negative ion population in the atmosphere; oxygen and water vapor have a greater affinity for electrons than do nitrogen molecules.

Elimination of $n$ between Eqs. (5) and (6) gives

$$
E_{@ 1 \mathrm{~V} \mathrm{~cm}^{-1} \text { torr }^{-1}} L_{\text {high velocity ion }} \cong 0.75 \frac{k T}{\sigma} \quad \mathrm{V} \mathrm{m} \mathrm{N}^{-1} .
$$

For an $E / p$ of $1 \mathrm{~V} \mathrm{~cm}^{-1}$ torr $^{-1}$ at $293 \mathrm{~K}\left(20^{\circ} \mathrm{C}\right)$, the temperature of the air during the Allen-Ghaffar measurements,

$$
E_{@ 1 \mathrm{~V} \mathrm{~cm}^{-1} \text { torr }^{-1}} L_{\text {high velocity ion }} \cong 7.0 \mathrm{mV} \text {. }
$$

At an $E / p$ of $90 \mathrm{~V} \mathrm{~cm}^{-1}$ torr $^{-1}$, an ion moving a distance of one mean free path between collisions with air molecules under the influence of the local electric 


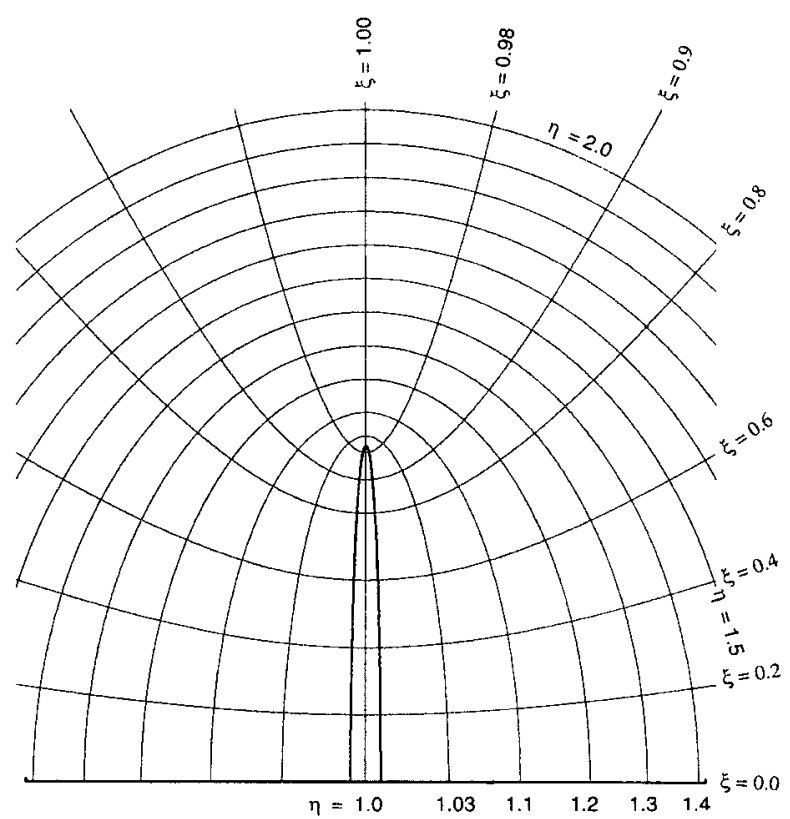

FIG. 8. An example of confocal ellipsoidal and hyperboloidal coordinates $\eta$ and $\xi$.

field would drop across a potential difference of about $0.63 \mathrm{~V}$. In so doing, it could acquire a kinetic energy contribution equal to the potential given up times the ionic charge $\left(1.6 \times 10^{-19} \mathrm{C}\right)$. This energy transfer can be written alternatively as that of $0.63 \mathrm{eV}$ (electron volt). Because the energy required for the ionization of a nitrogen molecule is about $14.5 \mathrm{eV}$ and that for an oxygen molecule is about $13.6 \mathrm{eV}$, it is obvious that the energies required for electron liberation are far less than the energy required to extract an electron from either a nitrogen or an oxygen molecule. Kip concluded, therefore, that his positive discharges began after electrons were liberated from negatively charged ions in the vicinity of his electrode's tip at the $E / p$ equivalent of about 0.6 eV.

With this information, it becomes of interest to investigate how the strength of the electric field varies with distance from the tip of a lightning rod.

\section{The variation of electric field strength around the tip of an air terminal}

When a curved conductor is exposed to an externally uniform electric field $E_{0}$ the field strength at the conductor tip is intensified greatly over that at locations far removed from the tip. The amount of intensification relative to that of the undisturbed field $\left(E_{\text {tip }} / E_{0}\right)$ is known as the field enhancement factor $k_{e}$. It is possible to calculate $k_{e}$ for some simple, symmetric conductor shapes such as a conducting hemispherical boss protruding above a conducting plane (for which $k_{e}=3.0$ ), but simple analytic solutions do not exist for vertical sections of cylinders. As a result, the lightning rods of

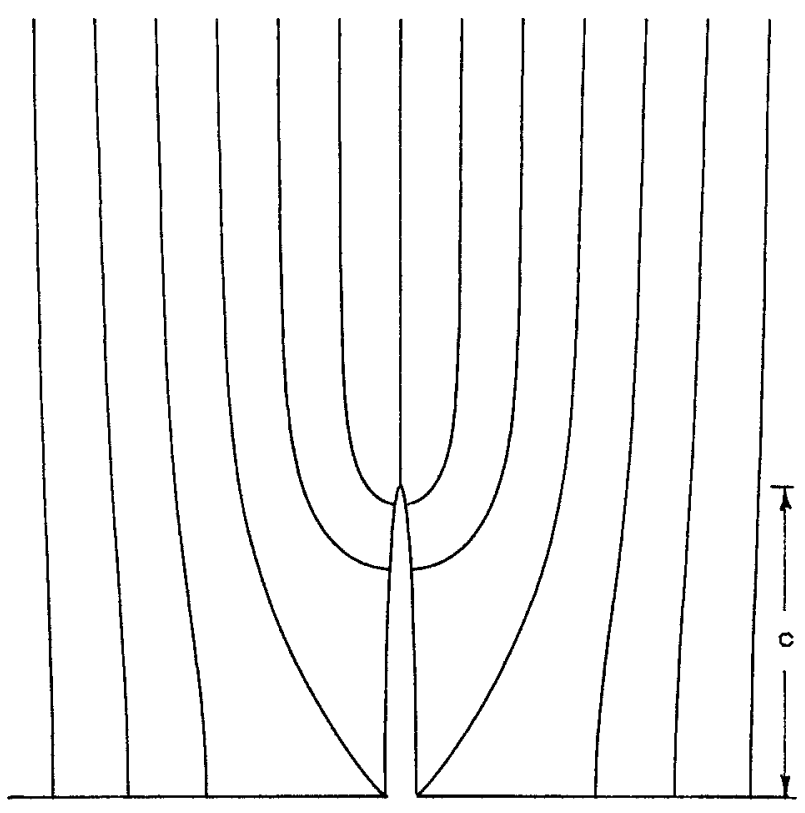

FIG. 9. A plot of the calculated electric field lines of force around a conducting, vertical prolate semiellipsoid exposed to a uniform vertically directed electric field prior to the onset of any discharges. The height-to-tip radius ratio for this ellipsoid is 500; $k_{e}$ of the electric field at the tip of the semiellipsoid has been calculated to be about 180.

interest cannot be treated analytically, but their geometry can be approximated by simulating a lightning rod with a conducting, vertical, prolate semiellipsoid (a shape for which an analytic solution does exist) having the same radius of curvature for the tip and the same tip height. The coordinate system used is shown in Fig. 8 , and the calculated electric field lines of force around such an ellipsoidal conductor are shown in Fig. 9.

With this assumption of the equivalent shape for the conductor tip, an approximate value for $k_{e}$ can be calculated by differentiating Smythe's (1950, 168-169) prolate semiellipsoid potential function with the use of the proper metrics. This function, in confocal ellipsoidal and hyperboloidal coordinates, is

$$
V=-E_{0} z\left(1-\frac{\operatorname{coth}^{-1} \eta-\frac{1}{\eta}}{\operatorname{coth}^{-1} \eta_{0}-\frac{1}{\eta_{0}}}\right),
$$

where $E_{0}$ is the strength of the uniform, external, axially directed electric field; $z$ is the height of the point of interest above a plane earth; $\eta$ is the location of the point of interest in ellipsoidal coordinates; $\eta_{0}$ is the ellipsoidal coordinate of the surface of the ellipsoid simulating the lightning rod; and

$$
\operatorname{coth}^{-1} \eta=\frac{1}{2} \log _{e}\left(\frac{\eta+1}{\eta-1}\right) .
$$

The calculated ellipsoidal $\left(E_{\eta}\right)$ and hyperboloidal $\left(E_{\xi}\right)$ 
components of the electric field in the air around the simulated lightning rod are given by

$$
\begin{aligned}
E_{\eta}=E_{0} \xi \sqrt{\frac{\eta^{2}-1}{\eta^{2}-\xi^{2}}}\left[1-\frac{\operatorname{coth}^{-1} \eta-\frac{1}{\eta}}{\operatorname{coth}^{-1} \eta_{0}-\frac{1}{\eta_{0}}}\right. \\
\left.+\frac{1}{\eta\left(\eta^{2}-1\right)\left(\operatorname{coth}^{-1} \eta_{0}-\frac{1}{\eta_{0}}\right)}\right]
\end{aligned}
$$

and

$$
E_{\xi}=E_{0} \eta \sqrt{\frac{1-\xi^{2}}{\eta^{2}-\xi^{2}}}\left(1-\frac{\operatorname{coth}^{-1} \eta-\frac{1}{\eta}}{\operatorname{coth}^{-1} \eta_{0}-\frac{1}{\eta_{0}}}\right) .
$$

The $\eta_{0}$ coordinate for the surface of the prolate ellipsoid is given by

$$
\eta_{0}=[1-(a / c)]^{-1 / 2},
$$

where $a$ is the radius of curvature of the tip, and $c$ is the length of the semimajor axis of the simulating prolate semiellipsoid (i.e., the height of the lightning rod tip).

The electric field at the tip of a semiellipsoid is concentrated as a result of the curvature and height of the conductor. At the top of the ellipsoid where the hyperboloidal coordinate $\xi$ equals 1.0 and $\eta$ equals $\eta_{0}, k_{e}$ can be calculated from Eq. (11) by taking the ratio of the field strength at the tip $E_{\text {tip }}$ to that of the undisturbed ambient field $E_{0}$ :

$$
k_{e}=\frac{E_{\mathrm{tip}}}{E_{0}}=\left[\eta_{0}\left(\eta_{0}-1\right)\left(\operatorname{coth}^{-1} \eta_{0}-\frac{1}{\eta_{0}}\right)\right]^{-1} .
$$

A plot of this relation is shown in Fig. 10.

To calculate the field strength at any point outside the ellipsoid, one first must determine the focal height of the ellipsoid and the value of $\eta$ at the desired point. The height of the focus of the ellipsoid $h_{f}$ is given by

$$
h_{f}=c / \eta_{0} \text {. }
$$

The $\eta$ coordinate for any point outside the ellipsoid is defined by

$$
\begin{aligned}
\eta=\left\langle\left\{x^{2}+z^{2}+h_{f}^{2}+\left[\left(x^{2}+z^{2}+h_{f}^{2}\right)^{2}-4 h_{f}^{2} z^{2}\right]^{1 / 2}\right\}\right. \\
\left.\quad \div 2 h_{f}^{2}\right\rangle^{1 / 2},
\end{aligned}
$$

where $x$ is the horizontal distance from the axis of the vertical semiellipsoid. The $\eta$ coordinate can vary from

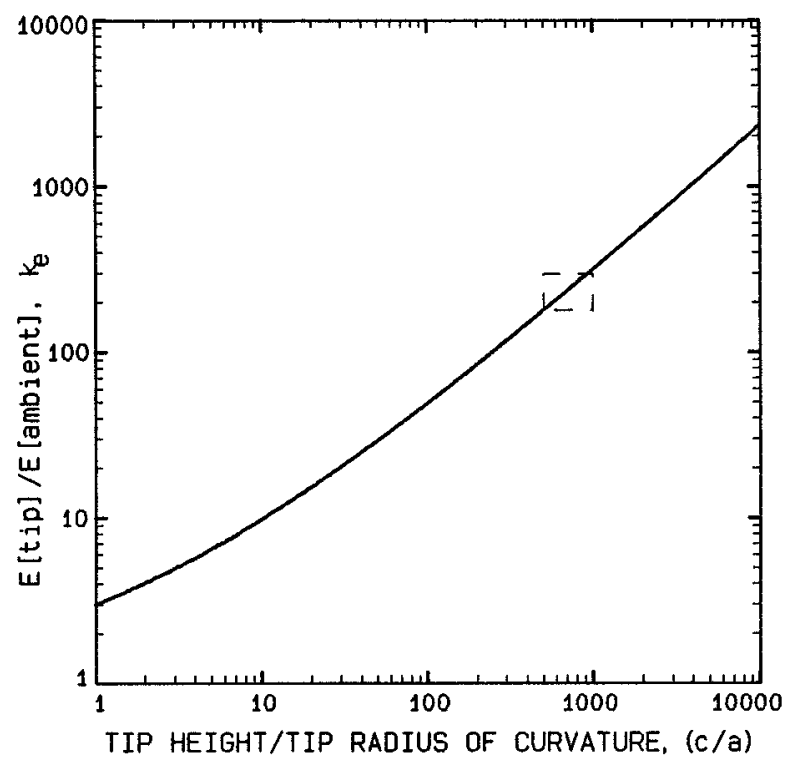

FIG. 10. Plot of the height-to-tip ratio $c: a$ vs $k_{e}$ at the tip of conducting, prolate semiellipsoids exposed to an axially directed, ambient electric field prior to the onset of discharges. The dashed rectangle identifies the configuration bounds that are recommended here for lightning rods.

$\eta_{0}$ to infinity (which denotes a flat plane, high above the tip of the semiellipsoid). For a location on axis, directly above the ellipsoid, Eq. (16) simplifies to

$$
\eta=\frac{z}{h_{f}}=\frac{z}{c} \eta_{0} .
$$

The hyperboloidal coordinate varies from 0 to 1 ; it is defined as

$$
\xi=\frac{z}{\eta h_{f}}
$$

Calculation of the strength of the electric field at various distances $r$ above the tip's center of curvature relative to the field strength at the tip indicates that

$$
\frac{E_{r}}{E_{\text {tip }}}=\frac{a}{2 r-a}
$$

for distances within 50 tip radii from sharp electrodes.

In Fig. 11, a plot is shown of the calculated $E_{r}$ versus $r$, measured in units of the tip radius of curvature $a$. From this figure it can be seen that the strongly enhanced fields around the tip of a sharp electrode decrease rapidly with distance; the field strength at a distance of one tip radius from the tip surface has a strength that is onethird of that at the tip. On the other hand, since the field strengths scale inversely with the tip radius, they do not decrease as rapidly above blunter electrodes. This behavior leads to an interesting result: at distances in excess of $6 \mathrm{~mm}$ or so, the enhanced field in the absence of ionization around a $10-\mathrm{mm}$-radius rod is much stronger than is the field above a $0.1-\mathrm{mm}$-radius rod at the 


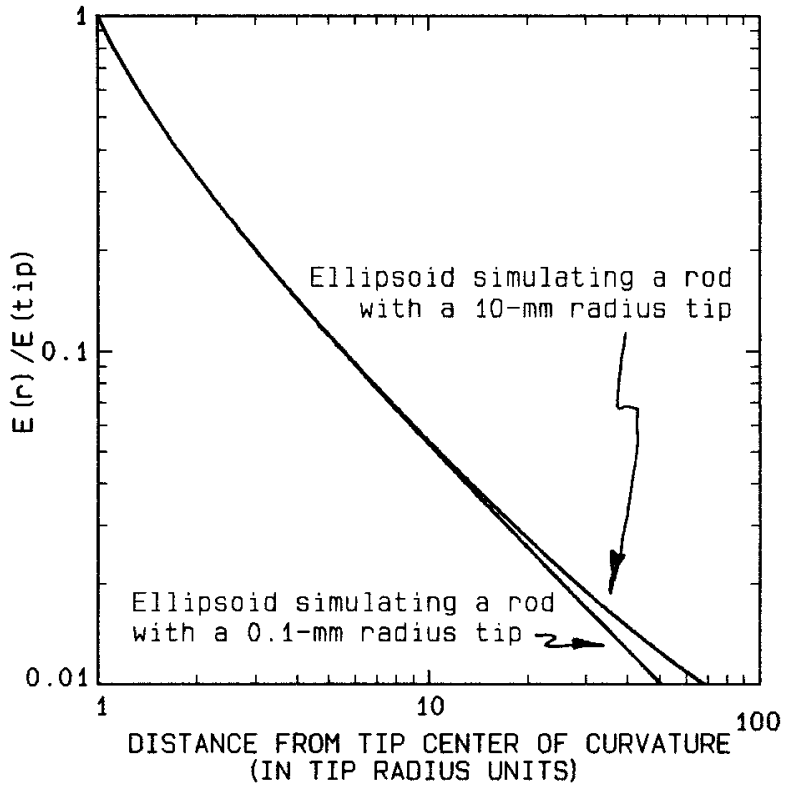

FIG. 11. Plots showing the decrease of the distorted field strength with distance above the tips of two, 6.4-m-high, prolate semiellipsoidal electrodes exposed to an axially directed ambient electric field $E_{0}$ prior to the onset of discharges. The field strength above the sharper electrode is given by $E_{\text {tip }} /[(2 r / a)-1]$ out to distances in excess of 50 radii.

same height and exposed to the same ambient electric field. Illustrations of this result are shown in Figs. 12 and 13. This finding is important because, from the earlier discussion, the continued propagation of positive streamers depends on the strength of the electric field ahead of the positive ions at the tip. It appears that the stronger fields above blunt rods outside the point discharge emission zone favor the propagation of any streamer that forms.

These calculations for the variation of field strength above the tip of an electrode subjected to a uniform electric field were used to estimate the thicknesses of the limited volumes in which electron avalanches occur, that is, Kip's (1938) "sensitive volumes." These estimates from the laboratory measurements are presented in Table 2.

From Table 2 it can be seen that, at the onset of electron avalanches, the strong electric fields necessary for the initial liberation of electrons from negative ions do not exist at distances greater than $0.25 \mathrm{~mm}$ from any of these tips; Kip's sensitive volumes are concentrated right around the electrode tips. We now turn to a study of the point discharge processes.

\section{An examination of the point discharge processes}

The dependence of the point discharge currents (in still air) on the square of the applied electric fields, as indicated from the work by Warburg, Chapman, and others, suggests that two different processes involving

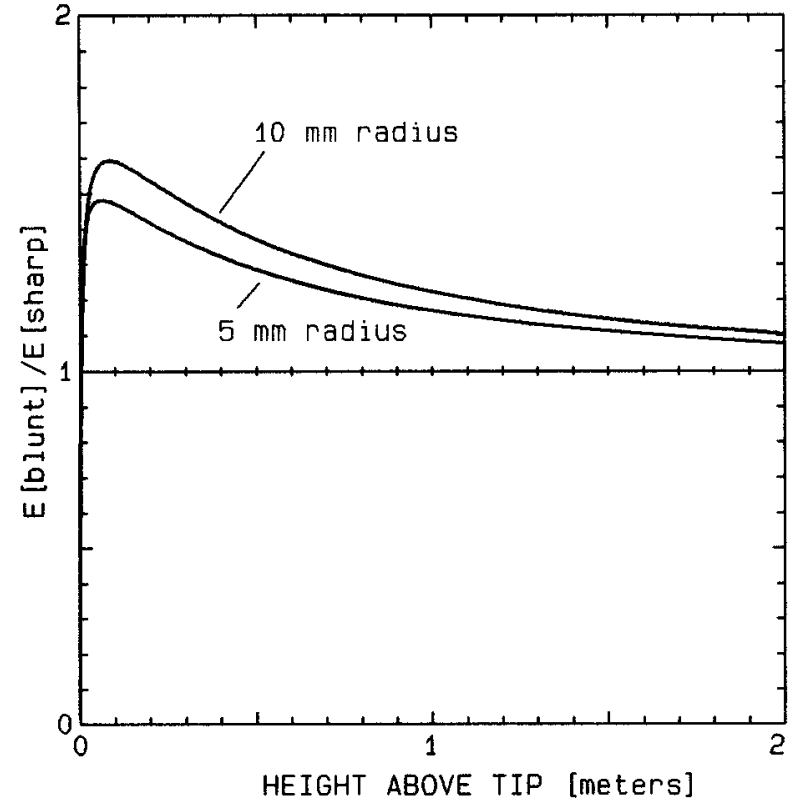

FIG. 12. Plots of the strengths of the electric fields above the tips of two blunt semiellipsoids relative to that above the tip of a similar but sharp semiellipsoid with a 0.1 -mm-radius tip, when all were exposed to the same, uniform electric field oriented in the direction of the ellipsoids' major axes, prior to the onset of discharges. The semimajor axis length of each semiellipsoid was $6.4 \mathrm{~m}$.

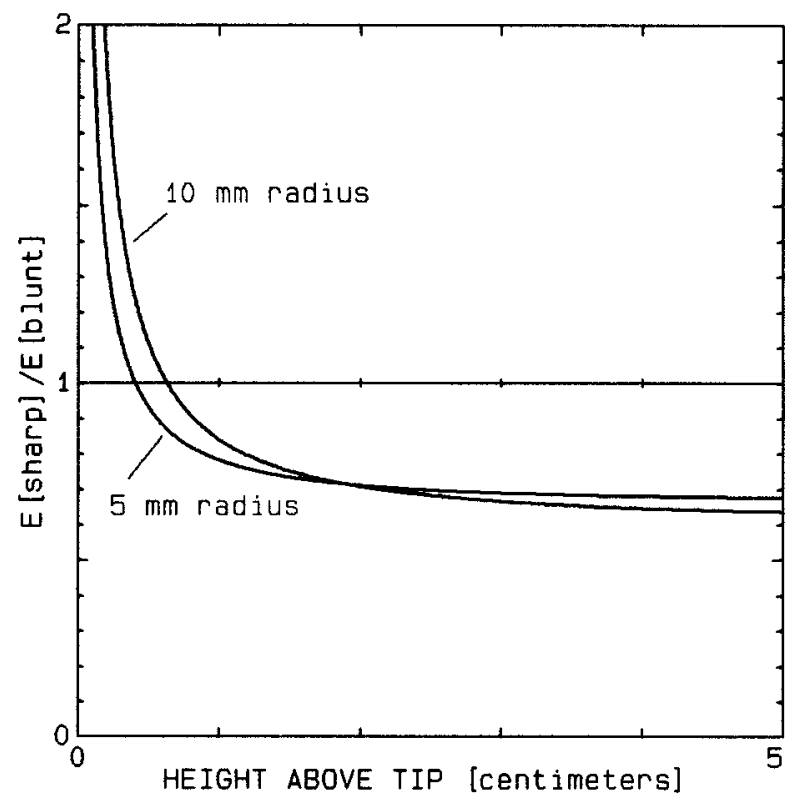

FIG. 13. Plots of the relative strength of the electric field just above a sharp semiellipsoid with a 0.1-mm-radius tip compared with those above the tips of two similarly exposed, blunt semiellipsoids when all were exposed to the same, uniform electric field oriented in the direction of the ellipsoids' major axes, prior to the onset of discharges. The semimajor axis length of each semiellipsoid was $6.4 \mathrm{~m}$. 
TABLE 2. Calculations of the thicknesses of the sensitive volumes. Here, $N_{90}$ is defined as the distance, in tip-radius-of-curvature units, from the tip center of curvature to the location where the local $E / p$ is $90 \mathrm{~V} \mathrm{~cm}^{-1}$ torr $^{-1}$ (i.e., the location where electron avalanches may start). Also, $\Delta r_{90}$ is defined as the actual distance from the tip where the local $E / p$ is $90 \mathrm{~V} \mathrm{~cm}^{-1}$ torr $^{-1}$ (i.e., the location where electron avalanches may start). This value is the calculated thickness of the region that Kip (1939) defined as the sensitive volume in which free electrons are produced around the tip.

\begin{tabular}{|c|c|c|c|c|c|c|}
\hline Tip radius $(\mathrm{mm})$ & $c / a$ & $k_{e}$ & $E_{\text {onset }}\left(\mathrm{kV} \mathrm{m}^{-1}\right)$ & $\begin{array}{c}E / p_{\text {tip }} \\
\left(\mathrm{V} \mathrm{cm}^{-1} \text { torr }^{-1}\right)\end{array}$ & $N_{90}$ & $\Delta r_{90}(\mathrm{~mm})$ \\
\hline$\sim 0.01$ & $\sim 14000$ & $\sim 3150$ & 25.5 & $\sim 1250$ & 7.4 & 0.06 \\
\hline 0.0625 & 2260 & 634 & 40.2 & 395 & 2.7 & 0.11 \\
\hline 0.125 & 1130 & 351 & 49.0 & 267 & 2.0 & 0.12 \\
\hline 0.25 & 565 & 197 & 61.3 & 187 & 1.5 & 0.14 \\
\hline 0.50 & 282 & 112 & 82.2 & 143 & 1.3 & 0.15 \\
\hline
\end{tabular}

the strength of the ambient field operate during these emissions. This supposition is supported by an examination of the charge burst emissions such as those shown in Figs. 3, 4, and 5, which suggest that the amount of positive ion space charge created in each burst is dependent on the excess strength of the electric field above a threshold and the time required to clear this space charge is a function of the ion motions under the influence of the ambient electric field and wind. Chapman (1967) recognized the dependence of the current emissions on the ion velocity and proposed relations similar to Eq. (20) to fit his measurements:

$$
I=A_{F} \varepsilon h\left(E_{0}-E_{\text {threshold }}\right)\left[\left(K E_{0}\right)^{2}+v^{2}\right]^{1 / 2},
$$

where $A_{F}$ is a proportionality coefficient, $h$ is the height of the electrode, $\varepsilon$ is the permittivity of the air (8.85 $\mathrm{pF} \mathrm{m}^{-1}$ ), $K$ is the positive ion mobility [nominally about $1.4 \times 10^{-4} \mathrm{~m} \mathrm{~s}^{-1}\left(\mathrm{~V} \mathrm{~m}^{-1}\right)^{-1}$ for the conditions in Pilié's laboratory], and $v$ is the velocity of the wind past the tip of the electrode. Although Chapman calculated the $A_{F}$ coefficient values for various electrodes, he presented no analysis of their variations with electrode size. As a result, his relation is not directly useful for an analysis of these data. There are also some problems in Eq. (20). Chapman assumed that the ion mobilities were the same under strong electric fields as they are in weak, fine weather, electric fields, whereas Varney's (1953) measurements of the velocities of positively charged nitrogen ions indicate that their mobilities under strong fields may be as little as one-third of the weak-field values. Further, in his calculations, Chapman used the applied electric field strengths directly and did not consider the enhanced field strengths that acted on the ions at the tips of his electrodes. Nevertheless, Chapman provided an explanation for Warburg's relation given in Eq. (1), and, from Chapman's approach, we can propose a simplified model of the charge transfer processes during the burst mode.

\section{a. Pulse discharge regime relations}

For this model, we suggest that, after a free electron is liberated above the tip of the electrode, electron avalanches continue, leaving positive ions in their wake until the electric field caused by these ions so weakens the local field that the avalanches cease. The quantity of ion space charge created during such a burst can be estimated from the change in displacement charge on the tip that occurs as the local field decreases from that at avalanche onset to that at cessation.

We now consider a vertical, cylindrical, metal lightning rod, formed into a hemisphere at its top, that is exposed to an ambient, uniform, vertical electric field with strength of $E_{0}$. The displacement charge $Q_{d}$ induced by the electric field on the hemispherical tip is taken to be

$$
Q_{d}=\varepsilon \pi a^{2} k_{e} E_{0}
$$

where $a$ is the radius of the hemisphere.

We invoke Kip's (1938) observations that point discharges commence after the strength of the local electric field at the tip exceeds a critical value $E_{\text {onset }}$ and cease when the tip field strength decreases below a "turn-off" value $E_{\text {cessation }}$. Next, we assume that an upper limit on the amount of new space charge in the air that surrounds the tip following an electron avalanche episode is equivalent to the change $\Delta Q_{d}$ in the displacement charge on the tip, which is approximated by

$$
\Delta Q_{d}=\varepsilon \pi a^{2}\left(E_{\text {tip }}-E_{\text {cessation }}\right) .
$$

Here, $E_{\text {tip }}$ and $E_{\text {cessation }}$ cannot be measured directly, but the ambient field strength, $E_{0}$ can be measured, and values for $k_{e}$, the field enhancement factor at the tip, can be calculated. The product $k_{e} E_{0}$ then can be used for an estimate of $E_{\text {tip }}$. Similarly, $E_{\text {cessation }}$ can be approximated by use of the strength of the ambient external electric field $E_{\text {ex }}$ (the ambient field strength when point discharge activity extinguishes) times $k_{e}$. (In the current laboratory measurements, it was found that $E_{\text {intercept }}$ was equal to $E_{\text {ex }}$.) With these approximations, Eq. (22) can be rewritten as

$$
\Delta Q_{d}=\varepsilon \pi a^{2} k_{e}\left(E_{0}-E_{\text {ex }}\right) .
$$

In still air, the positive ion space charges will move radially outward under the influence of the local electric field, which decreases with the distance $r$ from the center of curvature, and also as a result of their repulsion from each other. The duration of the interval between pulses probably is controlled by the clearing of ions from around the tip, because a period of many microseconds 
TABLE 3. Calculations of the ion clearing time-electric field strength product.

\begin{tabular}{ccccccc}
\hline \hline $\begin{array}{c}\text { Tip radius of } \\
\text { curvature }(\mathrm{mm})\end{array}$ & $k_{e}$ & $\begin{array}{c}\text { Field strength at } \\
\text { onset of steady cur- } \\
\text { rent }\left(\mathrm{kV} \mathrm{m}^{-1}\right)\end{array}$ & $\begin{array}{c}\frac{I}{E_{0}\left(E_{0}-E_{\text {ex }}\right)} \\
{\left[\mathrm{fA}\left(\mathrm{V} \mathrm{m}^{-1}\right)^{-2}\right]}\end{array}$ & $E_{0} t_{c}\left(\mathrm{~V} \mathrm{~s} \mathrm{~m}^{-1}\right)$ & $\begin{array}{c}\frac{a}{E_{0} t_{c}} \\
{\left[\mathrm{~m}^{2}(\mathrm{~V} \mathrm{~s})^{-1}\right]}\end{array}$ & $t_{c}$ at $E_{\text {onset }}(\mu \mathrm{s})$ \\
\hline$\sim 0.01$ & $\sim 3150$ & 25.5 & 1.134 & $\sim 0.008$ & $\sim 0.0013$ & $\sim 0.3$ \\
0.0625 & 634 & 40.2 & 1.308 & 0.053 & 0.00118 & 1.3 \\
0.125 & 351 & 49.0 & 1.362 & 0.11 & 0.00112 & 2.2 \\
0.25 & 197 & 61.3 & 1.384 & 0.25 & 0.00101 & 4.0 \\
0.50 & 112 & 82.2 & 1.414 & 0.55 & 0.00091 & 6.7 \\
\hline
\end{tabular}

is required for the ion migrations whereas the electron avalanches occur quite rapidly; many of the measured avalanches were completed within one microsecond or less.

In this model, the mean current $\langle I\rangle$ is defined by the change $\Delta Q_{d}$ in displacement charge on the tip of the rod caused by a charge-burst sequence divided by the time $\Delta t$ required for clearing the resulting positive ions that shield the tip from the ambient electric field:

$$
\langle I\rangle=\varepsilon \pi a^{2} k_{e}\left(E_{0}-E_{\mathrm{ex}}\right) / \Delta t .
$$

Because the strength of the electric field above the tip of the simulated elliptical electrode (in the absence of any ions) scales in terms of the tip radius of curvature, $\Delta t$ can be defined as

$$
\Delta t=\frac{\Delta N a}{\langle v\rangle},
$$

where $\Delta N$ is the number of tip radii $a$ that the positive ions travel in the interval between point discharge bursts, and $\langle v\rangle$ is the mean ion velocity, which here depends on the strength of the local electric field acting on the ions and on any wind moving past the tip. This relationship leads to

$$
\langle I\rangle=\frac{\Delta Q_{d}}{\Delta t}=\varepsilon \pi a k_{e}\left(E_{0}-E_{\mathrm{ex}}\right) \frac{\langle v\rangle}{\Delta N} .
$$

To evaluate Eq. (26), $\langle\boldsymbol{v}\rangle$ and $\Delta N$, neither of which can be measured directly, need to be known. Therefore, in this analysis, the experimentally determined, ion-clearing times $\Delta t$ are used in Eq. (24). We turn now to a consideration of the glow regime currents.

\section{b. Glow discharge regime relations}

The laboratory experiments discussed in section $2 \mathrm{~d}$ showed that, as the applied field became stronger, the frequency of bursts increased and the time between bursts became so short that the bursts, in effect, became continuous discharges. In the glow regime, the entire tip of the electrode appears covered with a luminosity that indicates that electronic excitation is occurring over the entire area of the tip under the influence of the local electric fields; it suggests that photoionization processes are involved. Therefore the equivalent area for induction of a near-hemispherical tip can be used with the calculated field enhancement factor $k_{e}$ and the experimen- tally determined slopes of the $I / E$ versus $E$ plots in Fig. 7 to calculate relative ion-clearing times $t_{c}$ and to investigate how they vary with tip radius. Inserting the slope $I / E_{0}\left(E_{0}-E_{\text {ex }}\right)$ from the emissions plot for a given electrode into Eq. (24) gives

$$
\left[\frac{I}{E_{0}\left(E_{0}-E_{\text {ex }}\right)}\right] E_{0}=\frac{\varepsilon \pi a^{2} k_{e}}{t_{c}},
$$

which can be used to obtain the product of $t_{c}$ and the strength of the applied field $E_{0}$, provided that $E_{0}$ is equal to or greater than $E_{\text {onset }} / k_{e}$ :

$$
E_{0} t_{c}=\frac{\varepsilon \pi a^{2} k_{e}}{\left[\frac{I}{E_{0}\left(E_{0}-E_{\text {ex }}\right)}\right]} .
$$

The $E_{0} t_{c}$ values calculated for the five electrodes used in the laboratory measurements are shown in Table 3 together with the values for $t_{c}$ calculated for $E_{\text {tip }}$ equal to $E_{\text {onset }}$ for each electrode. (For these calculations it was assumed that $k_{e}$ did not change with the onset of ionization; if the $k_{e}$ values had decreased with the creation of ions, the calculated field-clearing time products would have decreased proportionately.) The ratio $a / E_{0} t_{c}$ in Table 3 has mobility units but is not a measure of the true, positive ion mobility. It is of interest, nevertheless, that this pseudomobility ratio decreases with increasing tip radius. From the calculations of $E_{0} t_{c}$ for rods at a given height, it appears that the calculated relative time $t_{c}$ required for ion clearing (s) varies with the tip radius $a(\mathrm{~m})$ as

$$
t_{c} \cong \frac{2940}{E_{0}} a^{1.13}=\frac{a^{1.13}}{\left(3.4 \times 10^{-4}\right) E_{0}},
$$

which suggests that $\langle v\rangle / \Delta N$ for the positive ions migrating under the influence of the electric fields around these electrodes in still air is approximately equal to 3.4 $\times 10^{-4}\left[\mathrm{~m} \mathrm{~s}^{-1}\left(\mathrm{~V} \mathrm{~m}^{-1}\right)^{-1}\right]$ times $E_{0}$. As a result, Eq. (24) can be rewritten for the still-air, glow regime as

$$
\langle I\rangle=\varepsilon \pi a^{0.87} k_{e}\left(E_{0}-E_{\mathrm{ex}}\right)\left(3.6 \times 10^{-4}\right) E_{0} .
$$

One conclusion that can be drawn from these laboratory measurements is that, although ions are emitted in weaker electric fields from sharp-tipped electrodes, they are cleared away much more rapidly than they are around blunter ones that have the same height and ex- 
posure. The effect this finding would have on lightning protection can now be considered; we turn now to an examination of lightning return strokes.

\section{The initiation of a return stroke}

An interesting situation arises when the ambient electric field intensifies so rapidly that the ion formation and migration processes are not sufficient to limit the strength of the field around the tip. When the electric fields above the positive ions produced by earlier electron avalanches have become so strong (probably greater than an $E / p$ of $90 \mathrm{~V} \mathrm{~cm}^{-1}$ torr $^{-1}$ ) that new electrons are liberated at greater distances, the new avalanches will create extended columns of positive ions farther from the tip. As Kip (1939) pointed out, such a growth of the positive ion regions outward effectively extends the electrode tip in the direction of the field, along the positive ion "trails." As a result, this process can produce plasma streamers that continue to propagate as long as the field strengths ahead of their tips are sufficient to produce adequate electron avalanches ahead of the streamers.

When the intensifying field is caused by an initiating, negative stepped leader descending from a thundercloud, the resulting positive streamer arising from a grounded electrode can intensify and propagate as a positive leader to meet the approaching stepped leader, with the energy required for the ionization coming from the ambient electric field. When the two leaders meet, electrons from successively higher portions of the negative leader will pass down the conducting path toward the earth, heating the channel and creating the upwardgoing luminosity called the return stroke. A consistent treatment of the processes involved has been given recently by Bondiou and Gallimberti (1994).

The formation of a positive leader depends on the development of a strong electric field that acts on the positive ions around the tip of an electrode; it therefore is worth estimating the rates of field intensification required to exceed the field-limiting ion-transfer rates from the air terminals. For this exercise, the time rate of increase in the displacement charge on the terminal tip is given by

$$
d Q_{d} / d t=d\left(\varepsilon \pi a^{2} k_{e} E_{0}\right) / d t=\varepsilon \pi a^{2} k_{e} d E_{0} / d t .
$$

Stronger electric fields acting on the ions will produce new electron avalanches ahead of them, thereby creating more positive ions farther from the tip. Therefore, from Eqs. (24) and (31), the condition for initiating the propagation of a positive streamer in still air may be that the field must intensify faster than it is limited by the ion current such that

$$
d E_{0} / d t>\frac{E_{0}-E_{\mathrm{ex}}}{\Delta t}
$$

Since $E_{0}$ intensifies greatly during the approach of a negative stepped leader, it eventually dominates the $\left(E_{0}\right.$
$\left.-E_{\text {ex }}\right)$ term. In this regime, the critical rate of field intensification for streamer launching, in effect, becomes

$$
\left(d E_{0} / d t\right)_{\text {critical }}>\frac{E_{0}}{\Delta t}
$$

which can be rewritten as

$$
\frac{1}{E_{0}} \frac{d E_{0}}{d t}>\frac{1}{\Delta t}
$$

this equation indicates that, for the initiation of a streamer, the fractional rate of electric field intensification must exceed the rate $1 /(\Delta t)$ at which ions are cleared.

\section{Electric field intensifications caused by negative leaders}

At the current time, no measures of the field intensification rates that occur during the initiation of a lightning strike exist (although direct determinations of these are possible), but Gallimberti (1979) earlier reported that field intensifications in excess of $10^{11} \mathrm{~V} \mathrm{~m}^{-1} \mathrm{~s}^{-1}$ were required for the formation of long sparks in his laboratory.

From Coulomb's law, one can obtain an estimate of the field intensification that would be produced by a point charge $Q$ at a height $H$ descending vertically toward a flat earth at a velocity $v_{Q}$ :

$$
|d E / d t| \cong \frac{Q v_{Q}}{\varepsilon \pi H^{3}} .
$$

Similarly, the strength of the electric field $E_{0}$ on the earth directly beneath the point charge $Q$ is

$$
E_{0}=\frac{Q}{2 \pi \varepsilon H^{2}} \text {. }
$$

Accordingly, when an elevated point charge descends above a conducting plane and induces corona discharges from an exposed tip just above the plane, the condition that the fractional rate of ambient electric field intensification exceed the rate at which ions are cleared from above the tip is

$$
\left|\frac{1}{E_{0}} \frac{d E_{0}}{d t}\right|=\left|\left(\frac{Q v_{Q}}{\varepsilon \pi H^{3}}\right) /\left(\frac{Q}{2 \varepsilon \pi H^{2}}\right)\right|=\left|\frac{2 v_{Q}}{H}\right|>\frac{1}{\Delta t} .
$$

Under this criterion for the initiation of a streamer from a given lightning rod, the field-intensification characteristic time defined by the ratio $H /\left(2 v_{Q}\right)$ must be less than the ion-clearing time. From Eq. (37), the fractional rate of electric field intensification at the earth below a stepped leader at a height of $30 \mathrm{~m}$ (the height used in the 1997 NFPA 780 Lightning Protection Standard as the nominal minimum "distance over which the final breakdown of the initial stroke occurs") and descending at the rate of $3 \times 10^{5} \mathrm{~m} \mathrm{~s}^{-1}$ (Uman 1969; Berger 1977) is about 20000 per second. It is expected that in this 
situation successful, upwardly propagating, positive return-stroke leaders would not be launched to meet a negative stepped leader from any lightning rod underneath for which the ion-clearing time was much less than $(1 / 20000)$ s (i.e., much less than $50 \mu \mathrm{s})$. When the relative ion-clearing time-tip radius relation given in Eq. (29) is combined with Eq. (37), the condition for the initiation of a leader (at the conditions during the measurements: a pressure of about 0.85 atm and a temperature of $290 \mathrm{~K}$ ) may be that

$$
\frac{a^{1.13}}{\left(3.4 \times 10^{-4}\right) E_{0}} \cong \Delta t>\frac{H}{2 v_{Q}} .
$$

The preceding exercise can provide an explanation as to why none of the sharpened rods in the test were struck by lightning but several blunter rods in their vicinity have been struck repeatedly. The calculated ion-clearing times for the blunt rods (several milliseconds for tip diameters greater than $10 \mathrm{~mm}$ at the 6.4-m heights) are much longer than the $16-\mu$ s intervals measured for the sharp, UL-approved Franklin rods. Further, the electric fields at heights greater than $1 \mathrm{~cm}$ above these blunt rods at the onset of the ionization would become stronger than those over the sharp rods because of the bluntrod geometry and because the locally strong fields at the tips of the sharp rods were limited by the emission and migration of the positive ions. As a result, if the fields intensify so rapidly after the onset of ionization that electrons are liberated from the air ahead of the residue of the initially formed positive ions before they have time to migrate, new electron avalanches can form farther from the tip, creating new regions of positively charged ions at ever greater distances. Under rapidly strengthening electric fields, this process can continue until it results in the formation of a streamer of positive ions propagating in the direction of the electric field and becoming an upward-going, return-stroke leader.

From all of the earlier studies, it appears that the essential requirement for the initiation of a streamer is that the electric fields ahead of the ions intensify faster than the ions can move to counteract the intensification; the essential requirement for the propagation of a leader is that sufficiently strong electric fields for the liberation of free electrons continue to exist ahead of its tip. After a leader has become well developed and an appreciably conductive plasma channel connects it to the electrode tip, however, the charge carried on the tip of the leader can create much of the electric field necessary for its continued propagation. When this condition occurs (as it does during the initiation of lightning by the rapid injection of wires into subcloud regions with strong electric fields), after the conductive channel has bridged atmospheric potential differences of several megavolts (Willett et al. 1999), a leader can propagate into regions where the strengths of the ambient fields are weaker than those found to be necessary initially by Phelps (1974) and by Allen and Ghaffar (1995).

\section{Discussion of improved lightning rod configurations}

\section{a. Requirements for strike protection against normal-polarity lightning}

Benjamin Franklin's significant contribution to lightning protection was his suggestion for erecting grounded metal rods to provide preferential paths to the earth for lightning. In retrospect, his method for providing this protection has been made less effective than it could be by his urging that the tips of lightning rods be sharpened; we think that his rods would provide better protection if they were not so effective in limiting the strength of the local electric fields. From the foregoing analysis, the requirements for the preferential formation of an upward-going, positive, return-stroke leader from the exposed object that is to receive lightning can now be listed. These requirements are that

1) the object be an exposed conductor of electricity that is connected to the earth;

2) very strong, upwardly directed, electric fields develop in the air above the object's tip, with strengths sufficient to liberate electrons from negative ions in the air, creating electron avalanches and columns of positive ions that accumulate more rapidly than they are carried away by ion migration and repulsion processes; and

3) the electric field in the air just above the accumulation of positive ions intensify to strengths greater than Loeb's $90 \mathrm{~V} \mathrm{~cm}^{-1}$ torr $^{-1}\left(6.8 \mathrm{MV} \mathrm{m}^{-1}\right.$ at sea level) threshold necessary for the liberation of electrons from negative ions in air. The resulting positive leader streamer that develops can propagate to meet a downcoming, negative stepped leader if the strength of the electric field ahead of the positive tip continues to be above the level required for electron avalanche formation.

To meet requirement 2 , it is desirable that the upper portion of a preferred strike object be exposed to the atmospheric field in such a manner that the field strength at the top is increased greatly over the ambient value even before the approach of an initiating lightning stepped leader. Most of the lightning strikes to the competing, nominally 6.4-m-high lightning rods were to those with hemispherical tip diameters that ranged between 12.7 and $19 \mathrm{~mm}$, although blunter rods with 25.4mm-diameter, hemispherical tips received two strikes during this study. The tip height-to-tip radius of curvature ratios $c: a$ for the rods that were struck by lightning ranged between about 500 and 1000. From these ratios, the useful field enhancement factors $k_{e}$ were calculated, and ranged between about 180 and 300. The best estimates at present are that the optimum tip heightto-tip radius of curvature ratio is about 680:1 and that the field strength enhancement at the top should be about 230-fold greater than the undisturbed, ambient field. A plot of the recommended ranges of field enhancement 


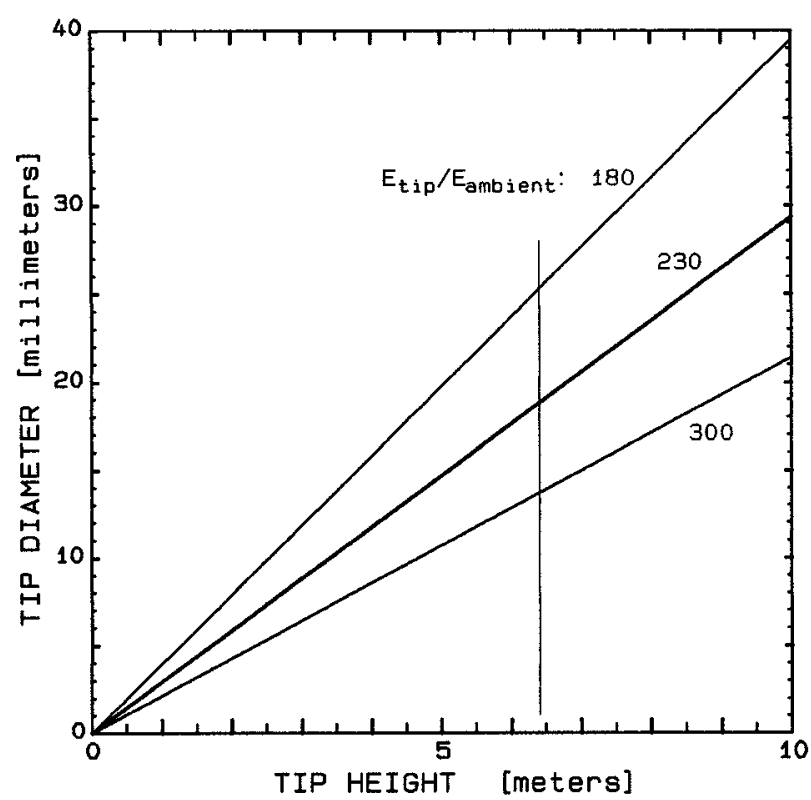

FIG. 14. Plots of the enhancement of the electric fields at the tips of vertical, conducting, prolate semiellipsoids, prior to the onset of discharges, as functions of the electrode tip height and diameter. The vertical line on the plot intersects the lines of constant field enhancement to show the range of tip diameters for the 6.4-m-high rods that were struck during this experiment.

for various tip heights and diameters is shown in Fig. 14. As an example illustrating the use of this chart, the intersections of the vertical line for the 6.4-m tip height with the contours of equal field enhancement define the range of tip diameters for the rods that were struck by lightning during the experiments.

The preceding analysis suggests that the rate of field intensification required for the launching of an upwardgoing positive leader is attained earlier and at lower values over blunter rods during the approach of a negative leader than it is over the currently used, sharptipped Franklin rods. Note also that, after a streamer is launched, the field strengths it would encounter at distances greater than $6 \mathrm{~mm}$ or so above a blunt rod are much stronger than those over a similarly exposed sharp rod. Therefore, during the approach of a negative leader, requirement 2 is met better with moderately blunt lightning rods than it is with any of the sharpened devices and wires that have been devised for lightning protection. On the other hand, very blunt rods (i.e., those with small height-to-tip size ratios) are not useful because point discharges from the rod tips are necessary to initiate positive-polarity return strokes, and these discharges do not occur readily from objects over which the ambient electric fields are not appreciably enhanced. In our view, either too much or too little electric field enhancement can decrease the lightning-protecting utility of a rod.

\section{b. Protection against the relatively infrequent, positive discharges}

We turn now to a brief consideration of protection against positive lightning. It is clear that negative leader discharges arising from an elevated lighting rod in response to approaching positive leaders would behave differently than would the positive discharges responding to normal, negative lightning. Under the influence of the strong field created by an approaching positive leader, electrons from the tip region would migrate quickly outward and, on collision with neutral air molecules, would free other electrons, creating relatively slow but inwardly moving positive ions in their wake. Because the electric fields acting on these fast-moving electrons must continue to be strong for them to continue the ionizations, it appears that the geometry of a blunt rod (with its stronger fields at distances of several millimeters in comparison with those over very sharp rods) will favor it to become the preferential receptor of positive strikes.

Another consideration is that because the laboratory measurements indicate that the ions formed around negative electrodes move faster than the positive ions created around positive electrodes of the same size and exposure, we expect that sharpened rods will protect themselves even better against positive polarity strikes than they do for normal, negative lightning. The ions around the negative electrodes clear in about two-thirds the time required for the normal-polarity ones, which suggests that $50 \%$ greater rates of field intensification are required for return-stroke emissions during positive strikes than are required for the normal, negative ones. As a result, moderately blunt rods may be expected to be the favored receptors for positive strikes as well as for the normal, negative discharges. Nevertheless, because no measurements that show how lightning rods interact with positive lightning yet exist, a study of their responses is needed.

\section{Conclusions}

We conclude, from this analysis and from the results of the lightning strike competition, that moderately blunt Franklin rods with tip height-to-tip radius of curvature ratios of about 680:1 (i.e., with electric field enhancements of about 230 fold at their tips) are more likely to furnish return strokes and therefore to provide better protection against lightning than can either very blunt ones or the traditional, sharp rods.

Acknowledgments. Many of the ideas discussed here about the nature of positive discharges, the effects of ion collisions with air molecules, and the conversion of positive space charges into plasma streamers were covered earlier in lucid and instructive papers, on the conduction and breakdown processes of gases, by A. F. Kip 
(1938, 1939), by A. von Hippel (1959), and by I. Gallimberti (1979).

We thank Charles H. Ackerman (East Coast Lightning Equipment Co.), Harold G. Van Sickle (AC Lightning Security Co.), Patricia L. Robbins (Robbins Lightning, Inc.), Thomas J. Cottle Jr. (Capital Lightning Protection Co.), Robert E. Cripe Jr. (Independent Protection Co., Inc.), Dennis Dillon (Bonded Lightning Protection Systems Co.), Dennis A. Jenkins (Power Technologies Co.), G. Maxwell (Maxwell Lightning Protection of Florida Co.), Will Priestley (Priestley Lightning Protection Co.), Tony A. Riley (Advanced Lightning Technology Co.), and D. J. Stepka (ERICO) for their generous support that made this study possible. We also are deeply indebted to William P. Winn and to Sandra Kieft for their many contributions to this study and to Marx Brook for his loan of the digitizer. We thank the reviewers for their insights and suggestions.

\section{REFERENCES}

Allen, N. L., and A. Ghaffar, 1995: The conditions required for the propagation of a cathode-directed positive streamer in air. $J$. Phys. D, 28, 331-337.

Berger, K., 1977: The earth flash. Lightning, R. H. Golde, Ed., Academic Press, 119-189.

Bondiou, A., and I. Gallimberti, 1994: Theoretical modelling of the development of the positive spark in long gaps. J. Phys. D, 27, 1252-1266.

Chapman, S., 1955: Discharge of corona currents from points on an aircraft or on the ground. Cornell Aeronautical Laboratory Rep. Series, CAL 66, Cornell Aeronautical Laboratory, Inc., Cornell University, $78 \mathrm{pp}$.

, 1967: Corona discharge from an isolated point. Cornell Aero- nautical Laboratory Rep. Series, CAL 161, Cornell Aeronautical Laboratory, Inc., Cornell University, 59 pp.

Cobine, J. D., 1958: Gaseous Conductors. Dover Publications, 606 pp.

Franklin, B., 1774: Experiments and Observations on Electricity. Reprinted 1941. Benjamin Franklin's Experiments, I. B. Cohen, Ed., Harvard University Press, 453 pp.

Gallimberti, I., 1979: The mechanism of the long spark formation. J. Phys., Colloque, 40, 193-250.

Harrison, M. A., and R. Geballe, 1953: Simultaneous measurement of ionization and attachment coefficients. Phys. Rev., 91, 1-7.

Hermstein, W., 1960: Die Stromfaden-Entladung und ihr Uebergang in das Glimmen (The streamer discharge and its transition into glow). Arch. Elektrotech., 45, 209-224.

Kip, A. F., 1938: Positive-point-to-plane discharge in air at atmospheric pressure. Phys. Rev., 54, 139-146.

_ 1939: Onset studies of positive point-to-plane corona in air at atmospheric pressure. Phys. Rev., 55, 549-556.

Loeb, L. B., 1935: The energy of formation of negative ions in $\mathrm{O}_{2}$. Phys. Rev., 48, 684-689.

NFPA 780, 1997: Standard for the Installation of Lightning Protection Systems 1997 Edition. National Fire Protection Association, $46 \mathrm{pp}$.

Phelps, C. T., 1971: Field-enhanced propagation of corona streamers. J. Geophys. Res., 76, 5799-5806.

- 1974: Positive streamer system initiation and its possible role in lightning initiation. J. Atmos. Terrest. Phys., 36, 103-111.

Schonland, B. F. J., and H. Collens, 1934: Progressive lightning. Proc. Roy. Soc. London, 114, 654-674.

Smythe, W. R., 1950: Static and Dynamic Electricity. McGraw-Hill, $616 \mathrm{pp}$.

Uman, M. A., 1969: Lightning. McGraw-Hill, 264 pp.

Varney, R. N., 1953: Drift velocity of ions in oxygen, nitrogen and carbon monoxide. Phys. Rev., 89, 708-714.

von Hippel, A., 1959: Conduction and breakdown in gases. Molecular Science and Molecular Engineering, A. von Hippel, Ed., John Wiley and Sons, 39-57.

Warburg, E., 1899: Ueber die Spitzenentladung (On point discharge). Wiedemann Annalen Phys. Chem., 67, 67-83.

Willett, J. C., D. A. Davis, and P. Laroche, 1999: An experimental study of positive leaders initiating rocket-triggered lightning. Atmos. Res., 51, 189-219. 